\title{
Down Syndrome
}

National Cancer Institute

\section{Source}

National Cancer Institute. Down Syndrome. NCI Thesaurus. Code C2993.

A chromosomal dysgenesis syndrome resulting from a triplication or translocation of chromosome 21. Down syndrome occurs in approximately 1:700 live births.

Abnormalities are variable from individual to individual and may include mental retardation, retarded growth, flat hypoplastic face with short nose, prominent epicanthic skin folds, small low-set ears with prominent antihelix, fissured and thickened tongue, laxness of joint ligaments, pelvic dysplasia, broad hands and feet, stubby fingers, transverse palmar crease, lenticular opacities and heart disease. Patients with Down syndrome have an estimated 10 to 30-fold increased risk for leukemia; most have symptoms of Alzheimer's disease by age 40. Also known as trisomy 21 syndrome. 